\title{
Internacionalización responsable: una perspectiva desde los TLC
}

Responsible Internationalization: From a FTA Perspective

Internacionalização responsável: uma perspectiva desde os TLC

\author{
Camilo Mejía Reátiga, ${ }^{* *}$ Carlos JaVier Velásquez, \\ MARJORIE ZÚÑIGA, ${ }^{* \star * *}$ VERÓNICA TORRES ${ }^{\star \star * * *}$
}

FECHA DE RECEPCIÓN: 6 DE NOVIEMBRE DE 2015. FECHA DE ACEPTACIÓN: 28 DE AGOSTO DE 2015

Doi: dx.doi.org/10.12804/esj18.01.2016.07

Para citar este artículo: Mejía, C., Velásquez, C., Zúñiga, M. y Torres, V. (2016). Internacionalización responsable: una perspectiva desde los TLC. Estudios Socio-Jurídicos, 18(1), 205-241. Doi: dx.doi.org/10.12804/esj 18.01.2016.07

\section{RESUMEN}

Este artículo presenta los primeros avances de un proyecto de investigación encaminado a determinar y describir la manera como los tratados de libre comercio, suscritos por Colombia con Estados Unidos y Canadá, promueven la creación de prácticas de responsabilidad social en las grandes empresas, en particular, las ubicadas en el distrito de Barranquilla, que exportan hacia dichos países. El artículo examina el grado de vinculación legal que existe en los tratados, en términos de explicitud de referencias a prácticas de la responsabilidad social y analiza su contenido a partir de las categorías del principal instrumento internacional de promoción de la responsabilidad social: el Pacto Mundial de la Organización de Naciones Unidas (Global Compact).

Palabras clave: TLC, Pacto Mundial, responsabilidad social, internacionalización.

* El presente artículo es producto del proyecto de investigación "Incidencia de los tratados de libre comercio suscritos con Estados Unidos y Canadá en las prácticas de responsabilidad social de las grandes empresas de Barranquilla", en el marco del área de integración y comercio internacional. Financiación interna de la Universidad del Norte. Agradecemos el apoyo de las asistentes de investigación Laura Cera Rodríguez, David García Torres, Meylin Ortiz Torres y Melina Ramos Eljaieck.

** $\mathrm{PhD}$ en Administración en el área de organizaciones. Docente investigador de la Universidad del Norte. Correo electrónico: cmejia@uninorte.edu.co

*** Doctor en Derecho. Docente investigador de la Universidad del Norte, director del Departamento de Derecho y Ciencia Política de la misma Universidad. Correo electrónico: cvelasquez@ uninorte.edu.co

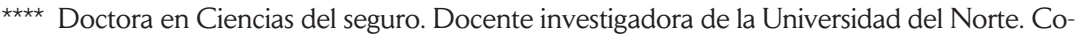
rreo electrónico: marjoriez@uninorte.edu.co

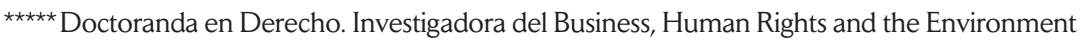
Group. Correo electrónico: mv22@gre.ac.uk 


\section{ABSTRACT}

This article presents the first results of a research aimed at understanding how the FTAs negotiated between Colombia and Canada, and Colombia and the United States generate Social responsibility practices from large enterprises in the city of Barranquilla knowingly exporting to those destinations. Specifically in this first hand out of results a literature review is performed aiming to understand the level of legal relationship that exists in both treaties in terms of the explicitness of references to social responsibility practices taking as reference the categories in which is recognized the United Nations Global Compact's ten principles.

Keywords: FTA, Global Compact, social responsibility, internationalization.

\section{RESUMO}

Este artigo os primeiros avances de um Projeto de Pesquisa encaminhado a determinar e descrever a maneira como os Tratados de Livre Comércio subscritos pela Colômbia com os Estados Unidos e a Canadá, promovem a criação de práticas de Responsabilidade Social nas grandes empresas, em particular as localizadas no Distrito de Barranquilla, que exportam para ditos países. O artigo examina o nível de vinculação legal que existe nos Tratados em termos de explicitação de referências a práticas à responsabilidade social, analisando seu conteúdo a partir das categorias do principal instrumento internacional de promoção da responsabilidade social: o Pacto Mundial da Organização das Nações Unidas (Global Compact).

Palavras-chave: TLC, pacto mundial, responsabilidade social, internacionalização. 
Este escrito tiene como objetivo principal determinar la inclusión y el grado de vinculación en los tratados de libre comercio -firmados por Colombia con Estados Unidos y Canadá- de compromisos en materia de responsabilidad social empresarial, a partir del análisis sobre el contenido del principal instrumento sobre el asunto: el Pacto Mundial de la Organización de Naciones Unidas (2013).

La cuestión resulta de alta relevancia, si se tiene en cuenta el auge experimentado por el Estado colombiano en la ratificación de tratados de libre comercio. ${ }^{1}$ Una de las medidas promovidas para evitar la ocurrencia de distorsiones (en la relación misma y hacia afuera) es la de incluir compromisos claros y concretos de responsabilidad social corporativa, es decir, obligaciones atinentes al desarrollo de prácticas desde las empresas, abiertas, transparentes y soportadas en valores éticos de respeto hacia la organización, los socios y la comunidad.

Como se señaló, el instrumento internacional por excelencia para ratificar el compromiso de los Estados y las organizaciones con la responsabilidad social empresarial es el denominado Pacto Mundial, resultado del trabajo de la Organización de Naciones Unidas (2013).

El Pacto Mundial es un documento de Derecho blando o Soft Law. En Derecho Internacional, Soft Law se refiere al conjunto de instrumentos que no tienen fuerza vinculante, utilizado por los Estados y las organizaciones internacionales en las relaciones internacionales contemporáneas (Boyle, 2010).

Esto es lo que la diferencia de normas de Derecho duro o Hard Law, pues siempre son obligatorias (tratados en vigor). Entre las normas de Derecho blando se encuentran declaraciones y resoluciones de la Asamblea General de las Naciones Unidas, códigos de conducta (Pacto Mundial),

1 Colombia tiene acuerdos comerciales firmado con: a.) Comunidad Andina de Naciones, de la cual forma parte junto con Perú, Ecuador y Bolivia. Venezuela se retiró; b) Acuerdo bilateral entre Colombia y México; c) TLC con Estados Unidos de Norteamérica; d) TLC con Canadá; e) Acuerdo Alianza Pacífico: Colombia, México, Chile y Perú; f) Acuerdo Comunidad Caribe (Caricom); g) Mercado Común del Sur; h) Colombia y Triángulo del Norte de Centroamérica (Salvador, Guatemala y Honduras); i) Acuerdo bilateral entre Colombia y Chile; j) Acuerdo entre Colombia y EFTA (Suiza y Liechtenstein). Acuerdos suscritos y pendientes de ratificación: TLC con Corea del Sur; TLC con Unión Europea; Acuerdo con Venezuela; Acuerdo con Noruega e Islandia, los otros dos miembros de EFTA. En este momento hay negociaciones con Turquía, Panamá, Israel y Costa Rica. Por último, se han planteado negociaciones con: Japón y China. 
directrices y recomendaciones de organismos internacionales. La importancia de estas normas radica en que desempeñan un rol influyente en el Derecho Internacional: pueden reflejar compromiso y buena fe de los Estados, contribuir a la conformación de costumbre internacional, compilar principios generales del Derecho Internacional o servir de precedente para el proceso de elaboración de tratados (Boyle, 2010).

El Pacto Mundial (ONU, 2013) es una iniciativa de ingreso voluntario, la cual provee un marco general para fomentar tanto el crecimiento sustentable de las organizaciones como su responsabilidad cívica en cualquier lugar del mundo.

La iniciativa apareció en el año de 1999 y, a partir de entonces, invita a adoptar diez principios universales relativos a la protección de los derechos humanos, las normas laborales, el cuidado del ambiente y la lucha contra la corrupción. Desde su creación, gran cantidad de empresas lo han acogido, en representación de diversos sectores de la economía y múltiples regiones geográficas.

\section{Planteamiento del problema}

Para cumplir con el objetivo general propuesto, se ha formulado el siguiente interrogante: jurídicamente, icuán vinculante es la normativa sobre prácticas de responsabilidad social establecida en los tratados de libre comercio firmados por Colombia con Estados Unidos y Canadá, en materia de protección de derechos humanos, de derechos laborales y del ambiente y de lucha contra la corrupción?

Con el fin de dar respuesta al interrogante general, se ha planteado una serie de preguntas subsidiarias o secundarias, encadenada a la respuesta principal:

1. ¿De qué manera (intensidad y extensión) incorpora el Pacto Mundial los asuntos relacionados con la protección de los derechos humanos, de los derechos laborales y del ambiente y con la lucha contra la corrupción?

2. ¿De forma expresa, los TLC celebrados por Colombia con Estados Unidos y Canadá incluyen prácticas de responsabilidad social de las empresas? Si lo hacen, ¿aluden al Pacto Mundial? 
3. En caso de no existir remisión explícita de los TLC en las materias señaladas, ies posible interpretar la existencia de una remisión implícita a los Principios contenidos en el Pacto Mundial u otro instrumento similar? De darse el último caso, ¿cuál es ese instrumento?

\section{Desarrollo}

En este apartado se examina cada uno de los interrogantes en el orden en el que fueron planteados. Para ello, se analizará el conjunto de fuentes secundarias recopiladas y sistematizadas.

\subsection{RSE y derechos humanos}

Tanto en intensidad como extensión, el Pacto Mundial (2013) abarca la protección de los derechos humanos. En el texto del instrumento se establecen dos Principios al respecto:

Principio 1: las empresas deben apoyar y respetar la protección de los derechos humanos fundamentales reconocidos universalmente dentro de su ámbito de influencia.

Principio 2: las empresas deben asegurarse de que sus empresas no son cómplices de la vulneración de los derechos humanos.

Como se ve, este par de Principios define un rol para la empresa en la protección general de los derechos humanos, lo que solía ser materia exclusiva de los Estados: respeto, promoción, protección y garantía de los derechos humanos.

El Pacto Mundial se adoptó en el seno de la ONU, en reemplazo de la Comisión de sociedades trasnacionales y el centro de sociedades transnacionales (1974), cuya función era investigar la acción de ese tipo de empresas. Este cambio ha sido bastante criticado, ya que se plantea como una forma de debilitar el accionar de la ONU frente a las violaciones de derechos humanos causadas por las empresas, evidenciado en la participación de las mismas en la aprobación y adopción del Pacto Mundial, para asegurarse de que no tuviera carácter vinculante en su contra (Teitelbaum, 2007). 
Ante la falta de normas obligatorias, los Principios del Pacto Mundial se presentan como una alternativa para llamar la atención de las empresas sobre sus posibles impactos en el área de influencia. Se espera que las empresas apoyen y respeten los derechos humanos; no obstante, la obligación de respeto, promoción, protección y garantía sigue a cargo del Estado (Corte IDH, 1986; Oficina del Alto Comisionado de las Naciones Unidas, Oficina del Pacto Mundial de Naciones Unidas, s. f.).

La relación de las empresas con la protección de los derechos humanos se deriva de las obligaciones contraídas por los Estados en los tratados. Como lo estableció el Comité de Derechos Humanos de la ONU (2004):

[L]as obligaciones positivas de los Estados Partes de velar por los derechos del Pacto sólo se cumplirán plenamente si los individuos están protegidos por el Estado, no sólo contra las violaciones de los derechos del Pacto por sus agentes, sino también contra los actos cometidos por personas o entidades privadas que obstaculizarían el disfrute de los derechos del Pacto en la medida en que son susceptibles de aplicación entre personas o entidades privadas (cursivas propias) (párr. 8).

De acuerdo con lo anterior, el Estado debe regular la actividad de las personas o entidades privadas - en este caso, la empresa-, para prevenir violaciones a los derechos humanos asociadas con estas. En la actualidad existen dos tipos de regulación jurídica para abordar el tema derechos humanos-empresa: en primer lugar, la tradicional coerción que ejercen los Estados mediante su justicia interna ante eventuales vulneraciones a los derechos humanos, frente a las cuales la empresa puede ser declarada directamente responsable y, en segundo lugar, por medio de la figura de la RSE, que otorga valor y buena reputación a la empresa.

En cualquiera de los dos supuestos, el respeto a los derechos humanos se circunscribe al Derecho Internacional de los Derechos Humanos y los instrumentos internacionales que lo componen.

El documento de referencia inicial del Pacto Mundial, cuando dispone que "[llas Empresas deben apoyar y respetar la protección de los derechos humanos reconocidos internacionalmente" es la Declaración Universal de los Derechos Humanos (DUDH) (Organización de Naciones Unidas, 1948). Esto es así, toda vez que la Declaración fue uno de los primeros 
textos suscritos sobre derechos humanos y porque es reconocida como fuente consuetudinaria del Derecho Internacional de los Derechos Humanos y del Derecho Internacional (CIDH, 2004). Hoy en día, se entiende ampliado a la Carta Internacional de los Derechos Humanos, que incluye la DUDH, el Pacto de Derechos Civiles y Políticos y el Pacto de Derechos Económicos, Sociales y Culturales (Oficina del Alto Comisionado de las Naciones Unidas, 2015).

En 2011 se adoptaron los Principios Rectores sobre las empresas y los derechos humanos de la ONU (en adelante, PR). Este documento, dirigido a los Estados y a las empresas, no tiene fuerza vinculante (Soft Law), pero goza de gran respaldo al haber sido adoptado por consenso en el Consejo de Derechos Humanos de la ONU (2011). Sin embargo, el Pacto Mundial se escoge como instrumento referencial de RSE porque los PR se encuentran en etapa de instrumentalización por medio de los planes nacionales de acción (Ramasastry, 2015). A su vez, los PR complementan los contenidos de aquel.

Por otro lado, la responsabilidad de las empresas, en cuanto a derechos humanos, ha sido un tema de extenso debate, debido a la cuestión entre voluntariedad u obligatoriedad (Martin-Ortega, 2008). Las empresas han promovido las iniciativas voluntarias como el Pacto Mundial (2000), objeto de estudio de este trabajo; las Directrices para las empresas multinacionales, de la Organización para la Cooperación y el Desarrollo Económico (1976) y la Declaración tripartita de principios sobre las empresas multinacionales y la política internacional, de la Organización del Trabajo (1977). Esto ha contribuido a mantener a las empresas alejadas de una regulación jurídica vinculante, como sucedió ante el fracaso del Borrador del Código de Conducta (1990) para las empresas transnacionales y la falta de implementación de las normas sobre responsabilidades de las empresas transnacionales y otras entidades comerciales en asuntos de derechos humanos de la Subcomisión de Promoción y Protección de los Derechos Humanos (2005), que aspiraban a ser instrumentos jurídicos obligatorios (Martin-Ortega, 2008).

En 2005, para continuar con el enfoque de iniciativas voluntarias, John Ruggie fue designado como relator para la cuestión de las empresas transnacionales y otras empresas. Tuvo como objetivos establecer estándares claros sobre las empresas y sus responsabilidades sobre derechos humanos 
(Aaronson y Higham, 2014) y promover una base conceptual sobre la cual pensar y actuar en el futuro (Ruggie, 2014).

El mandato culminó con la adopción de los PR en 2011. Estos articulan explícitamente el rol del Estado y de la empresa, pero no introducen cambios profundos en las obligaciones de cada actor. De igual forma, contiene el mismo marco jurídico al que remite el Pacto Mundial: la Carta Internacional de Derechos Humanos y la Declaración de la Organización Internacional del Trabajo (OIT) (Consejo de Derechos Humanos, 2011).

Este nuevo marco establece los tres pilares de la relación entre derechos humanos y empresa, con énfasis en obligaciones diferenciadas y complementarias: "Proteger, respetar y remediar" (Ramasastry, 2015, p. 244). El primer pilar establece la obligación del Estado de proteger a "todas las personas contra violaciones de derechos humanos bajo su territorio o jurisdicción por terceros, incluidas las empresas" (Consejo de Derechos Humanos, 2011, principio 12). La obligación de proteger es exclusiva del Estado, tradicional garante y sujeto del Derecho Internacional. Para dar cumplimiento a esta obligación, el Estado debe adoptar "todas las medidas apropiadas para prevenir, investigar, castigar y reparar esos abusos mediante políticas adecuadas, actividades de reglamentación y sometimiento a la justicia" (Consejo de Derechos Humanos, 2011, principio 1).

En lo relativo a las empresas, los PR le atribuyen la responsabilidad de respetar los derechos humanos. Esto quiere decir que "deben abstenerse de infringir los derechos humanos de terceros y hacer frente a las consecuencias negativas sobre los derechos humanos en las que tengan alguna participación" (Consejo de Derechos Humanos, 2011, principio 2). Las empresas no tienen obligaciones jurídicas internacionales ni son sujetos de Derecho Internacional. La materialización de la responsabilidad de respetar de las empresas se enmarca en el compromiso político, procesos de diligencia debida y mecanismos de reparación (Consejo de Derechos Humanos, 2011, principio 3). La diligencia debida exige a las empresas evaluar todos sus procedimientos para evitar que cualquier impacto directo o indirecto de su actividad resulte en violación de derechos humanos. Como plantea Martin-Ortega (2013), la diligencia debida es una conducta originalmente exigida al Estado en el desarrollo de su obligación de proteger y que ha sido extendida para la realización de la responsabilidad de respetar de las empresas. 
Sus responsabilidades en cuanto a derechos humanos se analizan desde la perspectiva de la subordinación a un Estado que debe proveer los mecanismos de acceso a la justicia y de reparaciones (judiciales o no judiciales), en el caso de que se configure una violación por un ente empresarial (Consejo de Derechos Humanos, 2011, principio 3). Como explica Ramasastry (2015), los Estados tienen la obligación de garantizar el respeto de los derechos humanos por parte de las empresas y estas, de hacer lo correcto y evaluar sus operaciones comerciales a la luz de los tratados de derechos humanos y, si llegaran a violar derechos humanos, deben proveer los mecanismos de reparación pertinentes. Así, se configuran los tres pilares propuestos por Ruggie.

De acuerdo con lo revisado, como respuesta al primer interrogante de este artículo se observa la incorporación intensa y amplia de normas de derechos humanos en el Pacto Mundial, por su referencia la Carta Internacional de Derechos Humanos que se complementa con los PR de la ONU.

\subsubsection{Los derechos humanos y su incorporación a los tratados de libre comercio con Estados Unidos y Canadá}

Durante las negociaciones del TLC de Colombia con Estados Unidos y Canadá, existió una fuerte presión política en temas relacionados con la dinámica de abusos a derechos humanos y, en especial, derechos laborales y sindicales (González, Salcedo y Rangel, 2011).

A pesar de lo anterior, las referencias a cláusulas sobre derechos humanos se limitaron a aspectos de carácter laboral (que serán expuestos en otro aparte de esta investigación); por fuera de ello, no existe referencia explícita o implícita a compromisos en relación con el tema en el marco del TLC.

Algunas reflexiones contrapuestas que tratan de explicar la falta de inclusión de cláusulas sobre derechos humanos giran alrededor de dos ideas: la materia eminentemente comercial de los tratados de libre comercio ${ }^{2} \mathrm{y}$

2 Al referirse en la sentencia de constitucionalidad del TLC con Estados Unidos, en relación con supuestas violaciones a los derechos humanos que emanarían del Acuerdo, la Corte Constitucional estableció: "En efecto, los aspectos de conveniencia, oportunidad, efectividad y utilidad de los acuerdos comerciales son materias ajenas a las funciones jurídicas que le han sido asignadas a la Corte Constitucional como guardiana de la integridad y supremacía de la Constitución (art. 241-10 superior). Su valoración corresponde constitucionalmente al Presidente de la República en ejercicio de la dirección de las relaciones internacionales (art. 189-2) y al Congreso de la República al disponer 
la falta de interés del Gobierno por proteger los derechos humanos en pro del beneficio de los países contratantes y sus empresas. ${ }^{3}$

El TLC es un tratado marco de las posibles alianzas comerciales que puedan surgir entre las empresas de los Estados contratantes. El análisis de posibles impactos contra los derechos humanos escapó del control de constitucionalidad de la Corte. Según esta, los efectos concretos del tratado no surgen a partir de su texto, sino de la materialización de los negocios que se celebren entre las empresas de cada Estado. ${ }^{4}$

Es importante analizar la importancia de incluir un marco jurídico en materia de derechos humanos en todas las actuaciones del Estado, ya que son obligaciones transversales y aplicables en todo momento, incluso en situaciones de emergencia o excepción, sobre todo en Colombia, inmersa en un conflicto armado y con antecedentes de violaciones a los derechos humanos bastante documentadas que involucran empresas sumidas en impunidad. ${ }^{5}$ La falta de cláusulas explícitas de protección a los derechos humanos en el cuerpo de los tratados denota una omisión lamentable.

Es cierto que las obligaciones convencionales sobre derechos humanos persisten para cada Estado; sin embargo, Estados Unidos y Canadá han suscrito obligaciones internacionales en menor medida y cantidad que

la aprobación o improbación de los tratados (art. 150-16). [...] la Corte no puede anticipar desde ahora la multiplicidad de complejidades que puedan derivarse de la aplicación del presente Acuerdo, por lo que, en su momento serán las distintas autoridades, en el marco de sus competencias, las que [...] deberán actuar [...] como garantía de los derechos fundamentales de todos los colombianos" (Corte Constitucional, 2008).

3 "[...] la falta de seriedad y voluntad política por los derechos humanos de las comunidades afectadas por el tratado y la inversión canadiense, se corrobora al observar el comportamiento del Estado colombiano frente a las denuncias, movimientos de resistencia y cuestionamientos de las comunidades afectadas por los abusos y violaciones por parte de multinacionales canadienses [...]. En estos hechos el gobierno ha tenido una tendencia fuerte de sincronizarse y respaldar a las multinacionales, restando importancia a la solicitud de las comunidades, con un mensaje contundente: una profunda preocupación por la rentabilidad de las empresas y una escasa pregunta por los derechos culturales, por las tradiciones indígenas y afrocolombianas, por la subsistencia agrícola de las comunidades o la sobrevivencia en la minería tradicional" (González et al., 2011 pp. 161-162).

4 "En efecto, siendo el control en estos casos abstracto y objetivo, una de cuyas características es la ausencia de elementos fácticos de aplicación concreta, en el control de constitucionalidad del presente Acuerdo la Corte enfrenta ciertos límites ocasionados por la inexistencia de elementos sobre los efectos concretos del mismo, que solo podrán determinarse al momento de su desarrollo y aplicación, no pudiendo la Corte ahora tomar una decisión plena inclusiva de todos los elementos de juicio respectivos" (Corte Constitucional, 2008).

5 Casos que vinculan a empresas como Chiquita Brands, Drumond Inc. o Coca-Cola incluyen graves violaciones al derecho a la vida, libertad, integridad, entre otros y pueden verse en la base de datos de Bussines \& Human Rights. 
Colombia. ${ }^{6}$ Esto tiene que ver no solo con la diferencia en el número de tratados ratificados, sino con la falta de jurisdicción general de organismos internacionales de derechos humanos para conocer de casos en contra de ambos Estados. Por ejemplo, Estados Unidos y Canadá no están sometidos a la jurisdicción de la Corte Interamericana de Derechos Humanos (Organización de Estados Americanos, 1969) y Estados Unidos tampoco lo está ante el Comité de Derechos Civiles y Políticos (Organización de Naciones Unidas, 1966). Luego, el cumplimiento de estándares de derechos humanos varía de un Estado a otro.

La única referencia a derechos humanos se encuentra en el Preámbulo del TLC con Canadá, en la cual los Estados "Reafirman sus compromisos en relación con el respeto por los valores y principios de la democracia y la promoción y protección de los derechos humanos y las libertades fundamentales, previstas en la Declaración Universal de los Derechos Humanos". ${ }^{7}$

El Preámbulo forma parte integral del tratado y sirve de fundamento para la aplicación e interpretación de todas las cláusulas contenidas en el mismo. ${ }^{8}$ La inclusión de referencia a la observancia de la DUDH en el Preámbulo no imprime obligaciones específicas sobre los derechos humanos que los Estados pudieran exigir a sus empresas, lo que equivale, de acuerdo con lo explicado, a una referencia de Soft Law que puede ser canalizado por la RSE.

Al respecto, el Artículo 816 del Tratado establece que cada parte (Canadá y Colombia) debe alentar a sus empresas a incorporar estándares internacionales de RSE, como declaraciones de principios aprobadas o respaldadas por las partes, incluidas aquellas que abordan derechos humanos (Congreso de la República, 2007, art. 816). En este aparte se puede apreciar una referencia explícita a RSE en materia de derechos humanos, cuya cláusula fue tenida por la Corte Constitucional como derecho positivo (obligatorio). Esto se traduce en la responsabilidad de los Estados de alentar

6 Número de tratados ratificados por cada país en derechos humanos en la OEA: Canadá: 14; Colombia: 40; Estados Unidos: 22 (Organización de Estados Americanos, 2013).

7 "Affirming their commitment to respect the values and principles of democracy and promotion and protection of human rights and fundamental freedoms as proclaimed in the Universal Declaration of Human Rights; Preámbulo. Tratado de Libre Comercio entre Colombia y Canadá" (Corte Constitucional, 2010).

8 El Preámbulo fue objeto de estudio para el control de constitucionalidad del tratado con Canadá y su ley aprobatoria (Corte Constitucional, 2010). 
y promover las prácticas de RSE en el marco del TLC, para contribuir al "cumplimiento de las obligaciones de las empresas en materia de derechos humanos" (Corte Constitucional, 2010).

Lo anterior nos lleva a preguntarnos: ¿cómo se integran la empresa y el respeto de los derechos humanos con los tratados de libre comercio? El panorama es el siguiente: a falta de cláusulas explícitas, solo quedan a la vista los condicionamientos que las empresas de Estados Unidos y Canadá les atribuyan a las empresas exportadoras de Colombia. Dependerá, entonces, de lo que definan las leyes internas o de las políticas de RSE que las empresas importadoras sostengan respecto a sus proveedores. La materialización y el compromiso de la empresa colombiana con los derechos humanos tendrán un incentivo eminentemente comercial, en la medida en que sus clientes del Norte así lo exijan.

\subsection{RSE y derechos laborales}

Cuatro de los diez Principios acogidos por el Pacto Mundial hacen referencia explícita a los derechos laborales. Estos son los siguientes:

Principio 3: las empresas deben apoyar la libertad de asociación y el reconocimiento efectivo del derecho a la negociación colectiva.

Principio 4: las empresas deben apoyar la eliminación de toda forma de trabajo forzoso o realizado bajo coacción.

Principio 5: las empresas deben apoyar la erradicación del trabajo infantil.

Principio 6: las empresas deben apoyar la abolición de las prácticas de discriminación en el empleo y la ocupación.

Los antecedentes sobre este asunto se remontan al año 1998, cuando la Organización Internacional del Trabajo (OIT) adoptó la Declaración de los principios y derechos fundamentales de los trabajadores, la cual obliga a todos los Estados miembros que hayan ratificado o no los tratados correspondientes. ${ }^{9}$ En virtud de lo anterior, el Pacto Mundial recoge los

9 Colombia, Estados Unidos y Canadá son Estados miembros de la OIT. Aquellos Estados miembros que no hayan ratificado uno o varios de los convenios fundamentales deberán presentar un memorial anual sobre la situación de dichos derechos y principios en el Estado (OIT, 2013). 
principios emanados de la citada Declaración, materializados en sendos convenios. Los principales convenios de la OIT que regulan su aplicación y cumplimiento son:

Tabla 1. Convenios de la OIT y su relación con principios de la Declaración

\begin{tabular}{|l|l|}
\hline \multicolumn{1}{|c|}{ Principios } & \multicolumn{1}{|c|}{ Convenio de la OIT } \\
\hline $\begin{array}{l}\text { La libertad de asociación, la libertad sindical y el derecho de } \\
\text { negociación colectiva. }\end{array}$ & Convenios 87 y 98 \\
\hline $\begin{array}{l}\text { La eliminación del trabajo forzoso u obligatorio. } \\
\text { La abolición del trabajo infantil. }\end{array}$ & Convenio 105 \\
\hline $\begin{array}{l}\text { La eliminación de la discriminación en materia de empleo y } \\
\text { ocupación. }\end{array}$ & Convenios 138 y 182 \\
\hline
\end{tabular}

Fuente: elaboración propia.

\subsubsection{La libertad de asociación, libertad sindical y el derecho de negociación colectiva}

De acuerdo con Ostau de Lafont (1996), el derecho de asociación es intrínseco a la naturaleza humana de seres sociales; por esa razón, resulta indispensable regular en conjunto la libertad de asociación y la libertad sindical, esta última como esencia del derecho de asociación.

El Convenio 87 de la OIT preceptúa el derecho de asociación tanto para empleadores como para trabajadores. ${ }^{10} \mathrm{El}$ texto señala que la legislación nacional no podrá limitar los derechos establecidos en el Convenio y su compromiso será determinar la gradualidad de la aplicación de las garantías del convenio sobre las Fuerzas Armadas y la Policía.

Por su parte, el Convenio 98 de la OIT celebrado en Ginebra el 8 de junio de 1949, y adoptado el 1 de julio del mismo año, precisa las conduc-

10 "Art. 2: Los trabajadores y los empleadores, sin ninguna distinción y sin autorización previa, tienen el derecho de constituir las organizaciones que estimen convenientes, así como el de afiliarse a estas organizaciones [...]. Art. 3: 1. Las organizaciones de trabajadores y de empleadores tienen el derecho de redactar sus estatutos y reglamentos administrativos, el de elegir libremente sus representantes, el de organizar su administración y sus actividades [...] 2. Las autoridades públicas deberán abstenerse de toda intervención que tienda a limitar este derecho o a entorpecer su ejercicio legal. Art. 4: Las organizaciones de trabajadores y de empleadores no están sujetas a disolución o suspensión por vía administrativa". 
tas antijurídicas en relación con el derecho en mención, sobre las cuales se deberá aplicar especial protección. Estas son:

1) Sujetar el empleo de un trabajador a la condición de que no se afilie a un sindicato, o a dejar de pertenecer al mismo.

2) Despedir o perjudicar a un trabajador en razón de su afiliación o participación sindical.

En este sentido, también establece que la legislación nacional deberá estimular y fomentar las organizaciones de empleadores y las organizaciones de trabajadores.

\subsubsection{La abolición del trabajo forzoso}

El Convenio sobre la abolición del trabajo forzoso 105 de 1957 obliga a todo Estado miembro de la Organización Internacional del Trabajo que lo haya ratificado a suprimir y a no hacer uso de formas de trabajo forzoso u obligatorio como medio de coerción o castigo, método de utilización de la mano de obra con fines de fomento económico, medida disciplinaria, castigo por huelga o medida de discriminación de cualquier tipo.

De la misma manera, obliga a que se tomen medidas eficaces para la abolición inmediata y total del trabajo forzoso u obligatorio. Además, regula la organización de sus miembros, su dirección y la forma como se revisará y controlará la aplicación de este mismo. También se tendrá un control sobre las ratificaciones, declaraciones y denuncias que comuniquen los miembros de la organización.

\subsubsection{La abolición del trabajo infantil}

Según lo dispuesto en el Convenio 182 de la OIT (2002), se tendrá por peores formas de trabajo infantil: las formas de esclavitud, la prostitución o pornografía infantil, actividades ilícitas y trabajos que pongan en peligro la salud, la seguridad o la moral de los niños. Cada Estado deberá implementar medidas para eliminar de forma prioritaria las formas de trabajo enunciadas; prestar asistencia directa para eliminarlas; asegurar a los niños liberados la enseñanza básica y gratuita, cuando esto sea posible, identificar a los niños expuestos al riesgo y tener en cuenta la situación especial de las niñas. 
El Convenio 138, celebrado el 26 de junio de 1973, exhorta a todos los miembros que lo han ratificado a la adopción de políticas nacionales tendientes a la abolición del trabajo infantil y al progresivo incremento de la edad mínima permitida para trabajar, en busca de un óptimo desarrollo físico y mental. Más adelante, el Convenio conmina a los miembros a especificar, mediante declaración ulterior, la edad autorizada en su territorio para la admisión laboral de menores; no puede ser esta una edad inferior a la necesaria para el término del ciclo escolar y, en caso de no especificarse, no podrá ser inferior a 15 años. Como excepción, la edad permitida para trabajar será de 14 años, cuando se alegue falta de desarrollo económico y sistemas educativos insuficientes. No obstante, también aclara que para todo tipo de trabajo que, por su naturaleza, pueda constituir un peligro para la salud, seguridad o moralidad del menor, la edad mínima será de 18 años.

Colombia es un país que, por sus características sociales, económicas y políticas, no es ajena a la problemática del trabajo infantil (IPEC, 2007). Cada año, cientos de niños deben salir de sus casas, no para ir a un centro de educación, sino para trabajar en diferentes oficios. Según cifras del Departamento Administrativo Nacional de Estadísticas (DANE), entre el año 2007 - cuando se negociaba el acuerdo comercial entre Colombia y Canadá- y 2009 -cuando ya se encontraba en vigencia el acuerdo- 1.050.147 niños trabajaban de forma clandestina. En solo dos años (2007 a 2009) aumentó esta problemática en un 34\% (CINDE, 2010).

\subsubsection{La eliminación de la discriminación en materia de empleo y ocupación}

El Convenio 100, celebrado el 29 de junio de 1951, exhorta a los miembros a utilizar los medios que consideren apropiados e idóneos ${ }^{11}$ para la promoción y la garantía de la igualdad de remuneración entre hombres y mujeres que desarrollen labores análogas. Para ello, mediante sus respectivas autoridades competentes, los miembros deben adoptar mecanismos que permitan la evaluación objetiva del empleo, de tal suerte que se puedan determinar las diferencias legítimas aplicables a las tasas salariales.

El Convenio 111, celebrado el 25 de junio de 1958, define el término "discriminación" como cualquier modalidad de exclusión o diferenciación

11 Medidas como legislación nacional y contratos colectivos de los trabajadores, entre otros. 
en razón de raza, sexo, religión, opinión política, ascendencia nacional u origen social que tenga como fin la segregación en el ámbito laboral. ${ }^{12}$ Incluye en estas distinciones las que cada Estado pueda acordar, previa consulta a organizaciones representativas tanto de empleadores como de trabajadores. Además expresa que aquellas que se hagan en razón de las competencias exigidas para ciertos trabajos no serán consideradas como discriminatorias. Por último, el Convenio establece como no discriminatorias las que recaigan sobre una persona debido a una legítima sospecha ligada a la posible comisión de hechos que atenten contra la seguridad del Estado y aquellas señaladas a causa de la constatación de situaciones o condiciones que justifiquen la necesidad de una protección o asistencia especial (edad, invalidez, etc.).

\subsubsection{Los TLC y su referencia a la protección a los trabajadores}

Revisados los Principios del Pacto Mundial en el ámbito laboral, se analizará el contenido del TLC tanto con Estados Unidos como con Canadá, para dar respuesta al interrogante inicial planteado en esta investigación.

La firma de estos tratados significó una enorme resistencia en el país, pues supuso la ampliación de las reformas laborales implementadas por los Gobiernos en los últimos catorce años. La principal oposición emana de la teoría que asocia el resultado de las reformas en comento con un cambio en la producción nacional por la extranjera, un aumento de la informalidad, una sustitución masiva del trabajo y un debilitamiento de la organización sindical. En este contexto, se presentan las remisiones que hacen los tratados al Derecho Laboral.

\subsubsection{TLC Colombia-Estados Unidos}

Se dedica el Capítulo XVII del acuerdo comercial al tema denominado "Asuntos laborales". En el Artículo 17.1, las partes reafirman sus obligaciones como miembros de la OIT y, por tanto, su compromiso con la protección de los principios y derechos laborales internacionalmente reconocidos. ${ }^{13}$

12 Dicho ámbito incluye, para efectos del convenio, los medios de capacitación profesional, las fases de admisión al empleo y las condiciones de trabajo.

13 También se reafirman los Estados parte en su autonomía legislativa para efectos de la 
En el Artículo 17.2, denominado "Aplicación de la legislación laboral", se refiere a las pautas que deben regir la promoción del comercio en el territorio y entre los Estados parte, las cuales establecen el no debilitamiento de la legislación laboral vigente, so pretexto del fortalecimiento de las relaciones comerciales, además de la efectiva observancia de los derechos internacionales en el ámbito laboral.

El Artículo 17.3 señala las garantías procesales, define el deber de los Estados parte de asegurar el acceso a la justicia a quienes cuenten con un interés jurídicamente válido para exigir el efectivo cumplimiento de la legislación laboral vigente. Asimismo, las partes se comprometen a promover el conocimiento público de la legislación laboral y garantizar el debido proceso de sus asociados.

Por último, el Artículo 17.5 instituye un "mecanismo de cooperación laboral y desarrollo de capacidades", como una forma de respetar la legislación y la soberanía de cada parte. Esta estrategia estará desarrollada sobre la base de actividades que serán implementadas por el Consejo de Asuntos Laborales ${ }^{14}$ y podrán ir encaminadas hacia cualquiera de los siguientes asuntos: programas de asistencia técnica, intercambio de delegaciones oficiales; intercambio de información sobre normas; intercambio de estudios académicos, conferencias, seminarios, talleres, reuniones, sesiones de capacitación; proyectos de investigación e intercambio de tecnologías, entre otras. Estas estrategias propiciarán la participación de empleadores y trabajadores en lo que respecta a las áreas de cooperación laboral.

El TLC suscrito con Estados Unidos ha sido sujeto de críticas por varios sectores. En cuanto a ratificación de convenios internacionales que versan sobre asuntos laborales, López Medina (2013) ha indicado que Colombia ratificó 58 convenios de la OIT, mientras Estados Unidos solo 14, la mayoría sobre asuntos marítimos que no están vigentes.

Por tanto, se ha puesto en duda el compromiso adquirido por Estados Unidos frente a diversos aspectos, entre ellos, el principio de la no discriminación en el trabajo por razones de raza, sexo, religión, opinión política,

adopción o modificación de sus leyes, como también para mejorar las normas internas a partir de lo enunciado por la normatividad internacional.

14 El Consejo está integrado por representantes ministeriales -o su equivalente- de ambas partes. 
ascendencia nacional y origen social, ya que se ha logrado excluir esta temática de cada uno de los TLC que ha ratificado, como forma de salvaguardar su propio dumping social (Motta Cárdenas, 2009).

\subsubsection{TLC Colombia-Canadá}

El TLC suscrito entre Colombia y Canadá dedica el Capítulo XVI a los asuntos laborales. El Artículo 1601 se denomina "Afirmaciones" y ratifica las obligaciones de los Estados parte como miembros de la OIT, así como los compromisos asumidos en la Declaración sobre principios y derechos fundamentales del Trabajo.

En el Artículo 1602, ambas partes reconocen que es inapropiado incentivar el comercio o la inversión con base en el debilitamiento de la legislación laboral.

Existe una explícita inclusión de las normas sobre derechos laborales fundamentales. En el Artículo 1603 señala unos objetivos que promueven los compromisos internacionales asumidos por las partes para fortalecer su cooperación laboral, con especial atención al derecho de asociación sindical, pues el literal d busca promover el diálogo entre los sindicatos y el Gobierno. El anterior es un aspecto de especial relevancia, si se tiene en cuenta que Colombia es uno de los países más peligrosos para ejercer el derecho de asociación, según la OIT y diversas organizaciones no gubernamentales (Human Rights Watch, 2013). ${ }^{15}$

Sobre el particular, movimientos sindicales han afirmado que, con la firma del TLC entre Canadá y Colombia, en realidad no se están garantizando tales derechos. La información existente señala que, frente a los derechos laborales y de libertad sindical, el TLC ha sido visto como una recompensa al Gobierno y a los empresarios respecto a la violación de los mismos, al olvidar y dejar en la impunidad más de 2.700 asesinatos de sindicalistas y perpetuar las omisiones del Estado colombiano al cumplimiento

15 De acuerdo con información de la Confederación General del Trabajo (CGT), la Confederación de Trabajadores de Colombia (CTC) y la Central Unitaria de Trabajadores (CUT) en reunión sostenida con representantes del Canadian Labour Congress, en Bogotá, se afirmó: "Desde nuestra perspectiva, un comercio justo debe significar desarrollo y progreso de los derechos sociales, económicos, culturales y ambientales de la sociedad colombiana" (CGC, CGT y CUT 2009). 
de los convenios ratificados y a las recomendaciones y solicitudes directas hechas por los órganos de control de la OIT (CGC, CGT y CUT, 2009).

El Artículo 1604 indica obligaciones para las partes y, en general, señala el cumplimiento de los compromisos internacionalmente reconocidos que deben estar contenidos en la legislación laboral interna de cada país.

De lo expuesto se infiere que, aunque los tratados estudiados no hacen alusión expresa al Pacto Mundial, los principios que contemplan y que rigen para las partes devienen a este en perfecta armonía con los compromisos adquiridos como miembros de la OIT.

Nótese que los cuatro Principios del Pacto Mundial están contemplados en la Declaración de los principios y derechos fundamentales de los trabajadores ratificada por Colombia, Estados Unidos y Canadá, es decir, libertad de asociación y la libertad sindical y el reconocimiento efectivo del derecho de negociación colectiva; eliminación del trabajo forzoso u obligatorio; abolición del trabajo infantil y eliminación de la discriminación en materia de empleo y ocupación.

No obstante, preocupan algunos aspectos como los mencionados por Moreno (2007), quien indica que estos acuerdos forzarán a los países en vías de desarrollo a competir entre sí para atraer la inversión de Estados Unidos, con la oferta de salarios bajos y el desconocimiento de leyes laborales y ambientales internas.

Por lo anterior, Moreno (2007) considera que es deber de cualquier tratado de integración económica contemplar cláusulas que estimulen la generación de empleos dignos, suficientes y productivos, para descartar la competencia comercial que se vale de salarios y condiciones laborales deplorables. ${ }^{16}$

Ante este panorama, es urgente la implementación de los planes de acción y los mecanismos de vigilancia mencionados en los tratados, de modo que se haga un seguimiento real a la protección de los derechos laborales, cuyo punto central sea el trabajador y el Estado sea su mayor promotor. Unidos.

16 Se pudo observar que así sucedió en Guatemala, luego de la firma del TLC con Estados 


\subsection{RSE y ambiente}

Al revisar los diez Principios acogidos por el Pacto Mundial de la ONU, se observa que tres de ellos son dedicados a la protección del ambiente:

Principio 7: las empresas deberán mantener un enfoque preventivo que favorezca el medio ambiente: Este hace referencia al principio de prevención de los impactos ambientales por parte del sector empresarial. Bien se sabe que el mejor impacto a gestionar es aquel que no se produce, de allí que lo importante sea prevenir antes que remediar.

Principio 8: las empresas deben fomentar las iniciativas que promuevan una mayor responsabilidad ambiental. Sin perjuicio del principio de prevención, este hace referencia a que, si alguna empresa genera un daño ambiental, tiene el deber de repararlo; derivación del principio del contaminador-pagador, fundamental en los asuntos de protección ambiental.

Principio 9: las Empresas deben favorecer el desarrollo y la difusión de las tecnologías respetuosas con el medio ambiente: aplicación de varios de los principios de la política ambiental, en el sentido del uso de las mejores tecnologías disponibles (BAT, -siglas en inglés), de la obligación que les cabe a las empresas de actualizarse tecnológicamente y de usar aquellas que sean favorables con el medio ambiente.

De los anteriores presupuestos se puede concluir que existe intensidad y extensión en la incorporación de los temas ambientales al Pacto Mundial de Naciones Unidas. Como se señaló, de los diez Principios tres son dedicados al tema ambiental y consagran importantes asuntos como la prevención, la responsabilidad y la reconversión o actualización tecnológico-ambiental de las empresas.

Si bien los TLC firmados por Colombia con Canadá y Estados Unidos incorporan los principios de Responsabilidad Social Empresarial, no remiten de manera expresa al Pacto Mundial de la ONU. No obstante, tanto Colombia como Canadá y Estados Unidos reconocen la importancia del comercio internacional y de las oportunidades de implementar políticas coherentes, con objetivos sociales, económicos y ambientales.

En relación con los tratados, en particular, se resalta que en ambos instrumentos existe un capítulo para los asuntos ambientales: en el acuerdo 
comercial con Canadá es el XVII, mientras en el acuerdo con Estados Unidos, el XVIII.

\subsubsection{El ambiente en los tratados de libre comercio con Estados Unidos y Canadá}

\subsubsection{TLC con Canadá}

El Acuerdo de promoción comercial entre Colombia y Canadá, sus cartas adjuntas y sus entendimientos fueron suscritos en Lima (Perú) el 21 de noviembre de 2008. Un canje de notas que corrige el texto original fue firmado entre el 18 y el 20 de febrero de 2010. El Acuerdo definitivo fue aprobado mediante la Ley 1363 del 9 de diciembre de 2009 por el Congreso de la República de Colombia. Por último, la Corte Constitucional, encontró al tratado acorde con el ordenamiento jurídico del país (Corte Constitucional, 2010).

Como se anticipó, el TLC con Canadá dedica su Capítulo XVII a los asuntos ambientales (Artículos 1701 a 1704):

El Artículo 1701 es denominado "Afirmaciones" en el que se sostiene lo siguiente: a) las partes tienen derechos soberanos y responsabilidades de conservar y proteger su ambiente; b) a consecuencia de lo anterior, tienen obligaciones ambientales de conformidad con su legislación nacional, y c) en la misma forma que tienen obligaciones de conformidad con su legislación interna, también las tienen según lo establecido en los acuerdos multilaterales ambientales que hayan suscrito. El numeral 2 de este Artículo señala que las partes reconocen el apoyo mutuo entre políticas comerciales y ambientales y la necesidad de implementar el Acuerdo de forma compatible con la protección y conservación ambiental, así como el uso sostenible de sus recursos naturales.

El Artículo 1702, "No derogación", señala que ninguna parte podrá estimular el comercio o la inversión mediante el debilitamiento o la reducción de la protección contemplados en sus respectivas legislaciones ambientales. Debemos entender, entonces, que cualquier disposición incluida en los acuerdos en contravía de la legislación ambiental de los Estados o de sus tratados internacionales ambientales ratificados es inaplicable. 
El Artículo 1703 instaura la obligación de respetar los convenios ambientales que cada uno haya ratificado, sobre todo en lo relacionado con: a) la conservación, protección y mejora del ambiente en el territorio de cada parte, para el bienestar de las generaciones presentes y futuras; b) el compromiso de no dejar sin efecto leyes ambientales nacionales para incentivar el comercio o la inversión; c) la conservación y el uso sostenible de la diversidad biológica y la protección y preservación del conocimiento tradicional; d) el desarrollo, la conformidad con y el cumplimiento de las legislaciones ambientales; e) la transparencia y la participación del público en asuntos ambientales, y f) la cooperación entre las partes para el avance de asuntos ambientales de interés común.

Por último, el Artículo 1704 señala que habrá un convenio específico sobre temas ambientales y, además, una comisión conjunta para hacer seguimiento a los compromisos que surjan de dicho acuerdo específico. El Artículo deja en claro la articulación que existirá entre el TLC y el Acuerdo sobre ambiente en el siguiente sentido: a) las partes reconocen la importancia de balancear las obligaciones comerciales y ambientales, afirman que un acuerdo sobre el ambiente complementa el TLC y que los dos se apoyan mutuamente, y b) la comisión conjunta considerará, según sea apropiado, los informes y las recomendaciones del comité de ambiente, establecidos en el Acuerdo sobre medio ambiente, respecto a cualquier asunto relacionado con el comercio y el ambiente.

Como se ve, hay un reconocimiento explícito que debe quedar materializado en un acuerdo adicional para balancear la relación comercioambiente. Buen avance.

\subsubsection{TLC con Estados Unidos}

Incorpora el tema de asuntos ambientales en el Capítulo XVIII, titulado "Medio ambiente". El objetivo general del capítulo es "el apoyo mutuo entre las políticas comerciales y las ambientales para lograr un desarrollo sostenible donde no resulte afectado el comercio entre las partes o el medio ambiente en alguna de ellas".

En el mismo sentido del tratado con Canadá, existe una adenda para "el entendimiento respecto a biodiversidad y conocimientos tradicionales", en clara alusión a los compromisos con la protección de la diversidad biológica 
y de los conocimientos de las comunidades tribales, que hoy día siguen sin estrategias efectivas de reconocimiento y protección.

El numeral 18.2 del Acuerdo está dedicado a los asuntos relacionados con la fiscalización y señala que se prohíbe a las partes dejar de aplicar su legislación ambiental, de forma que perjudique el comercio. Asimismo, se prohíbe promover el comercio con la disminución de la protección ambiental y añade en su apartado final que las partes mantienen el derecho a tomar sus propias decisiones sobre asuntos de investigación, procesales, regulatorios o de cumplimiento en temas ambientales.

Este es un punto preocupante, puesto que Colombia ha ratificado la mayor parte de los convenios ambientales internacionales, mientras sus contrapartes, no. Por otro lado, se abre el camino para que cada Estado tome sus propias decisiones sobre qué investiga, regula o sanciona. Tendríamos que estar pendientes de los intentos por aplicar esta cláusula cuando se intente implementar una medida menos garantista que signifique una posición de ventaja o provecho a partir de un menor control y protección.

El Artículo 18.3, punto 2, el cual trata lo relativo a la aplicación y observancia de las leyes ambientales, define que: "Las partes reconocen que es inapropiado promover el comercio o la inversión mediante el debilitamiento o reducción de las protecciones contempladas en sus respectivas legislaciones ambientales". Se puede ver que este Artículo contempla el Principio 7 del Pacto Mundial, ya que refleja la actitud preventiva de los Estados parte, consistente en reconocer la necesidad de existencia de actividades económicas como el comercio y la inversión, siempre respetuosas de los lineamientos de la legislación ambiental, los cuales están establecidos con rigurosidad para una efectiva protección del entorno y de los recursos.

En el Artículo 18.4, literal b, se exponen:

[...] incentivos, incluso basados en el mercado para estimular la conservación, restauración, uso sostenible y protección de los recursos naturales y el medio ambiente, tales como el reconocimiento público de las instalaciones o empresas que han demostrado ser superiores en su desempeño ambiental, o programas para el intercambio de permisos ambientales.

Este aparte guarda relación con el Principio 8 del Pacto Mundial, pues estos incentivos son una clara demostración de que los Estados parte del 
acuerdo desean propiciar una debida protección ambiental, por medio de los estímulos que le brindan al ciudadano.

A su vez, en el numeral 2 de este Artículo se instituye un compromiso en el que cada parte del Tratado deberá estimular "el mantenimiento, desarrollo o mejora de las metas y estándares utilizados para medir el desempeño ambiental". Con este compromiso se fomentan iniciativas que permiten verificar cuál ha sido el avance en la protección ambiental de cada Estado parte en un período; así, cada uno muestra resultados de sus avances sobre desempeño ambiental, lo que permitirá dar cumplimiento al compromiso adquirido en el acuerdo comercial; lo anterior también guarda relación con el Principio 8 del Pacto Mundial.

El numeral 18.4.5 crea el Consejo de asuntos ambientales, formado por representantes ministeriales. El Consejo debe discutir sobre la implementación del capítulo ambiental, enviar informes periódicos a la Comisión de libre comercio, posibilitar la participación del público y procurar resolver las consultas que se le formulen.

Por su parte, el numeral 18.6 está dedicado a los asuntos atinentes a la participación en los siguientes términos: "[...] se garantiza la provisión, recepción y consideración de las comunicaciones del público sobre asuntos ambientales. Cada parte se esforzará al máximo para responder favorablemente a las solicitudes de celebrar consultas realizadas 'por personas de esa parte".

En el Artículo 18.9, "Cooperación ambiental", se expone que "las partes reconocen la importancia de fortalecer sus capacidades para proteger el medio ambiente y promover el desarrollo sostenible, en armonía con el fortalecimiento de sus relaciones de comercio e inversión". Esto quiere decir que las partes reconocen que existe la necesidad de mejorar toda su política de acción para la protección del ambiente; esta concientización deja prever que todas las actividades deben incluir la finalidad última de proteger el ambiente, como se expone en el Principio 7 del Pacto Mundial.

El numeral 2 del Artículo 18.9 expresa que "las partes se comprometen a ampliar sus relaciones de cooperación en asuntos ambientales, reconociendo que ello les ayudará a alcanzar sus metas y objetivos ambientales compartidos, incluyendo el desarrollo y la mejora de la protección, prácticas y tecnologías ambientales"; se evidencia un principio de colaboración entre 
los Estados para utilizar tecnologías ambientales, en aplicación directa del Principio 9 del Pacto Mundial.

En cuanto a la adenda relacionada con observaciones sobre el entendimiento, es necesario señalar la postura que tienen los dos Estados frente a la protección de los conocimientos tradicionales y su estrecha relación con la biodiversidad. En este punto, no se logra verificar una coincidencia conceptual directa con los Principios del Pacto Mundial.

De todo lo expuesto, es posible destacar que el Tratado contiene compromisos concretos para Colombia, que deben llevar a promover instrumentos legales para ajustarlo a nuevos estándares de protección ambiental más altos.

Aunque no remite expresamente al Pacto Mundial, los principios establecidos en los Tratados guardan perfecta sincronía con los instaurados en dicho instrumento, por lo que es posible hacer la extrapolación o remisión.

Se muestra la necesidad de mantener un equilibrio entre comercio y ambiente y se busca un crecimiento comercial con conciencia ambiental, al menos, en términos del cumplimiento de los estándares propios de cada país.

\subsection{Lucha contra la corrupción}

\subsubsection{TLC con Estados Unidos}

En el marco del tratado de libre comercio entre Estados Unidos y Colombia, se hacen referencias implícitas y explícitas a algunas categorías en las que están circunscritos los diez Principios del Pacto Mundial.

Con respecto al Principio 10 del Pacto Mundial -Las empresas deben trabajar en contra de la corrupción en todas sus formas, incluidas la extorsión y el soborno-, las referencias implícitas en el tratado giran en torno de lo siguiente:

Artículo 2.15: administración e implementación de contingentes. En el numeral 2 (a) se establece que cada parte deberá asegurar que sus procedimientos para garantizar contingentes sean transparentes, estén disponibles al público, sean oportunos y no discriminatorios. Lo anterior implica una interpretación de la importancia que se otorga a los procesos de transparencia 
que, en últimas, es el mecanismo como se determina cuán propenso es a la corrupción un proceso empresarial determinado.

Artículo 2.17: empresas exportadoras del Estado. En este aparte del documento se alude a que las partes deberán trabajar juntas hacia un acuerdo en la OMC respecto a las empresas exportadoras del Estado, que asegure mayor transparencia de la operación y del mantenimiento de estas. El Artículo indica que el Estado como tal, desde lo público, propenderá por estrategias de transparencia que involucren procesos comprobables y susceptibles de seguimiento oficial.

Artículo 2.18: medidas de salvaguardia agrícola. En el numeral 6 del documento se afirma que una parte deberá implementar una medida de salvaguardia agrícola de manera transparente. Así las cosas, independiente de los mecanismos de protección que se utilicen, siempre se hace referencia a procesos que permitan tener claridad previa y hacer seguimiento en caso de conflictos, lo que brinda garantías para minimizar posibles problemas por corrupción.

Capítulo XIX. Transparencia. En cuanto a este tema, se establecen algunas consideraciones particulares:

Punto de enlace. Cada una de las partes establece un punto de enlace que será el encargado de manejar todos los temas asociados a la transparencia en las operaciones de comercio y gestión del tratado.

Publicaciones. Como parte esencial de un proceso transparente, el acuerdo establece la necesidad de hacer visibles las comunicaciones sobre propuestas y temas diversos dentro del alcance del tratado, haciendo énfasis en tiempos para considerar posibles contrapropuestas y respuestas de la contraparte.

Procesos administrativos. Siguiendo la línea de la consideración anterior, cada parte deberá asegurar que los procedimientos que se lleven a cabo sean informados por canales apropiados y con tiempo razonable, para que la contraparte pueda argumentar sobre ellos.

Revisión e impugnación. Las partes deben garantizar instancias y procedimientos transparentes para llevar a cabo conversaciones, impugnaciones o resolver controversias. Así mismo, se debe garantizar que no estén sujetas a los poderes judiciales oficiales de cada una de las partes y que sean completamente imparciales. 
Artículo 19.7: anticorrupción. En el numeral 2, las partes se comprometen a promover, facilitar y apoyar la cooperación internacional en la prevención y lucha contra la corrupción, lo que constituye una referencia explícita al Principio 10 del Pacto Mundial. Además, implica que las partes deben concebir los mecanismos para accionar la transparencia, en función de minimizar las probabilidades de ocurrencia de actos de corrupción.

Las partes declaran su compromiso de fomentar y apoyar espacios de diálogo y promoción de medidas anticorrupción, así como también su compromiso de respetar lo establecido en la Convención interamericana contra la corrupción, de 1996 y la Convención de las Naciones Unidas contra la corrupción, de 2003.

Las partes aceptan tomar las medidas legislativas necesarias para tipificar como delito un conjunto de contravenciones y comportamientos de funcionarios públicos: personas naturales que ofrezcan sobornos a funcionarios públicos, personas naturales que ofrezcan sobornos a funcionarios de la contraparte y, en general, cualquier persona que actúe bajo las condiciones que se catalogan como comportamientos corruptos. Asimismo, las partes se comprometen a tener los mecanismos para identificar esos comportamientos y procedimientos para garantizar la seguridad y el anonimato de los denunciantes de actos corruptos.

\subsubsection{TLC con Canadá}

El Tratado menciona el control sobre monopolios, la necesidad de concebir la transparencia como eje transversal del acuerdo y se concede especial valor a la autorregulación, a la innovación y al diálogo con los grupos de interés. En el cuerpo del tratado hay Artículos relacionados con la transparencia en los procedimientos de origen y facilitación del comercio (Artículo 409); obstáculos técnicos al comercio (Artículo 608); medidas de salvaguardia y defensa comercial (Artículo 705); telecomunicaciones (Artículo 1010); servicios financieros (Artículo 1111) y entrada temporal de personas de negocios (Artículo 1208).

De la misma manera, el párrafo 3 del Artículo 1403 especifica la importancia de la transparencia como principio rector de las contrataciones públicas, al señalar: "Una entidad contratante realizará las contrataciones 
públicas cubiertas por el capítulo XIV de manera transparente e imparcial que impida prácticas corruptas".

En materia de comercio por medios virtuales, las partes conceden especial valor a la transparencia, a la autorregulación, a la innovación y al diálogo con los grupos de interés, al afirmar:

Para facilitar el desarrollo del comercio electrónico, las partes reconocen la importancia de: (a) claridad y transparencia de sus marcos normativos. (b) alentar la autorregulación en el sector privado. (c) Innovación y competencia (d) asegurar que las políticas de comercio electrónico tengan en cuenta el interés de todos los usuarios, incluyendo empresarios, consumidores, ONG e instituciones públicas pertinentes (art. 1502 párrafo 2) (Ibarra, 2012, p. 96).

De acuerdo con Ibarra (2012), en el Artículo 1504 del tratado también se incluye el tema de la transparencia frente a los consumidores y su protección contra el fraude electrónico: "Las partes reconocen la importancia de mantener y adoptar medidas transparentes y efectivas para proteger a los consumidores de prácticas comerciales fraudulentas y engañosas en el comercio electrónico".

Por último, en el Capítulo XIX se indican los mismos parámetros que los contenidos en el correspondiente capítulo del documento firmado con Estados Unidos.

La inclusión de la lucha contra la corrupción en los Principios del Pacto Mundial de las Naciones Unidas conlleva el establecimiento de unos lineamientos operacionales en términos de transparencia que, a su vez, está soportado en la ética empresarial. Por tal razón, se requiere una conceptualización sobre la ética en el trasfondo de los modelos operacionales empresariales.

Ninguno de los elementos propuestos por los tratados sería suficiente si no existiera un catalizador que sirviera de unión en la construcción del "edificio conceptual y teórico" de la RS y las prácticas organizacionales. Esta investigación propone que dicho catalizador sea la práctica de la ética en la empresa. Por lo tanto, es importante partir de lo que aquí se entiende por esta.

Según Cortina (1997), "la ética, en un primer sentido, tiene por tarea mostrarnos cómo deliberar bien con objeto de hacer buenas elecciones. 
Pero [... ] no se trata sólo de elegir bien en un caso concreto, sino a lo largo de nuestra vida" (p. 18). Se es o no se es ético o socialmente responsable, pero no se puede ser ético o responsable en parte. Se trataría, entonces, de un proceso de seguridad en la palabra y las acciones del otro, en el que las organizaciones se consoliden como actores creibles y dignos de la confianza de los grupos de interés, sin perjuicio de tener mecanismos de escrutinio público, por ejemplo, mediante los sistemas de reporte en RS.

Desde la perspectiva humanista (en la cual la ética cumple un papel protagónico), se ha dicho que el objetivo de todos los seres humanos es la búsqueda de la felicidad. Las organizaciones están compuestas por seres humanos. Las empresas no toman decisiones, pues son una construcción del imaginario humano; son las personas que forman parte de ellas quienes eligen; por lo tanto, las disposiciones empresariales están cargadas de un gran componente subjetivo, humano, dado por percepciones, sentimientos, creencias, actitudes, etc. de los individuos que las toman.

Como lo expresa Méndez (2005):

[Lo anterior] no significa que los individuos formados en esta sociedad hayan abandonado su aspiración de alcanzar la felicidad, identificable en el capitalismo con la obtención de la mayor riqueza posible. Sin embargo, no todos los individuos identifican la felicidad con la riqueza (p. 142).

En este sentido:

[...] la felicidad es el fin último al que todos los hombres tienden y la ética se propone, en principio, ayudar a alcanzarla [...]. Por "felicidad" puede entenderse bienestar, una vida lo más placentera posible, repleta de satisfacciones sensibles, o bien el logro de la perfección, o también la autorrealización, es decir, alcanzar aquellas metas que nos parecen justas y deseables, produzca o no ese logro una satisfacción sensible (Cortina, 1997, p. 22).

Alcanzar esas metas justas y deseables que plantea Cortina implica un proceso sistemático de generación de confianza, que solo puede alcanzarse con el diálogo entre las partes involucradas en un determinado espacio y tiempo. El sistema económico en el que se desenvuelven las empresas no 
es el problema; de hecho, el modelo capitalista está basado en la credulidad entre las partes para poder alcanzar el mayor grado de eficiencia en las operaciones de las empresas. Cuando un proveedor ofrece unos productos o servicios, el comprador espera y confía a plenitud en que las condiciones de venta se cumplan, las especificaciones sean las pactadas, la información haya sido fiel y verdadera, etc., de manera que el negocio prospere para ambos. Cuando alguna de las partes miente o maneja la información para su propio y único beneficio, en contra de las expectativas, condiciones y necesidades del otro, se pierde la confianza y se genera la conducta antiética, que causan el canibalismo del propio sistema capitalista.

Para Sen (2009, citado en Flores Palacios, 2009):

[...] la operación eficiente de una economía está condicionada en gran medida por el recurso a contratos comerciales, a negociaciones y a un sentimiento de confianza. Ya sea que se trate de intercambio, de producción o de distribución, debemos observar el hecho de que es necesario que diferentes personas lleguen a concertar acuerdos entre ellos, y que deben confiar en que dichos acuerdos serán cumplidos (p. 8).

El mismo autor plantea algunos de los argumentos que se han sostenido a lo largo de esta investigación, respecto a la necesidad de la confianza y de la rendición de cuentas que, en términos de RS, pueden asimilarse a los reportes de sostenibilidad, para que el sistema capitalista funcione bien.

Este argumento muy limitado [al del ejemplo del panadero-cervecerocarnicerol no nos dice que los contratos comerciales orientados al lucro eliminarían la necesidad de un proceder basado en la ética. En primer lugar, es posible que la información de que dispone una de las partes sea limitada, y por ende se preste a la manipulación. En segundo lugar, si bien el comercio puede ser algo deseable sobre la base del interés propio de las partes, para que un sistema tradicional funcione bien y de manera confiable se requiere más que eso, léase confianza, buena voluntad y la rendición de cuentas de las partes involucradas. En tercer lugar, el ejemplo del panadero-cervecero-carnicero se refiere únicamente a los temas del comercio y del intercambio, sin aludir a los problemas adicionales que ocurren en los ámbitos de la producción y de la distribución (Sen, 2009, p. 9). 
El tema de la rendición de cuentas es esencial para la generación de confianza, en especial, porque permite el diálogo directo y en el más claro ambiente de colaboración y entendimiento. Mas "el hecho de que los grupos de interés confíen en la empresa no quiere decir que tengan una fe ciega. Es necesario que dispongan de datos significativos y veraces de las actividades para que vayan construyendo confianza" (Méndez, 2005, p. 147). Como referencia se tienen los grandes escándalos corporativos internacionales y nacionales; se han visto los casos de General Motors Colmotores - con la contaminación ocasionada por residuos tóxicos enterrados en inmediaciones de su planta en Cundinamarca- o las Empresas Promotoras de Salud (EPS) como Saludcoop - que habían sido reconocidas en el escenario nacional y el internacional por su gestión y RS-.

Es de extrema importancia el grado de claridad que puedan tener las empresas sobre los instrumentos de legitimización y rendición de cuentas en términos de la transparencia de sus actuaciones, pero no solo de los actos a posteriori, sino también -y más importante aún- de las acciones $a$ priori. Se evidencia la necesidad de vincular a los grupos de interés en los procesos de toma de decisiones. Por esto, es fundamental el tema de la comprensión de los stakeholders y las herramientas, los procedimientos y las metodologías para generar el diálogo con ellos y, de esa manera, abrir un primer espacio de confianza.

Ahora bien, todo lo anterior lleva a entender que existen puntos de conexión entre los TLC con Canadá y Estados Unidos y las categorías en las que está dividido el Pacto Mundial. Esos puntos permitirán entender hasta dónde, en la práctica, se propician iniciativas de responsabilidad social y cómo estas, a su vez, generan mayor competitividad o productividad a las grandes empresas que exportan a dichos destinos desde Barranquilla.

\section{Conclusiones}

Es dable afirmar que el Pacto Mundial es, sin duda, un instrumento que incorpora, con enorme acierto, gran amplitud y extensión, la protección

de los derechos humanos, los derechos laborales, el cuidado del ambiente y la lucha contra la corrupción. A pesar de lo anterior, no se verifica vin- 
culación legal alguna de este instrumento en el cuerpo de los tratados de libre comercio celebrados por Colombia con Estados Unidos y Canadá.

¿Lo anterior significa que, a partir de la ratificación de sus instrumentos, el comercio internacional prescinde de incluir prácticas de responsabilidad social para quienes participan de los beneficios de esta realidad mundial? En lo absoluto.

Al menos desde un punto de vista teórico, el cuerpo del TLC con Canadá plantea declaraciones proteccionistas de los ámbitos incluidos en el Pacto Mundial, mas el TLC con Estados Unidos no contiene remisiones explícitas a los derechos humanos y tampoco incorpora prácticas de RSE en la materia. De forma indirecta, los tratados señalan la necesidad de respetar y garantizar la legislación interna e internacional en estos ámbitos y, si bien el Pacto Mundial es de adhesión voluntaria y dispositivo de naturaleza Soft, también lo es que los países miembros de ONU en él tienen un punto de partida para incorporar las prácticas de responsabilidad en sus políticas y normas estatales.

Por otra parte, los tratados incorporan la creación de consejos y comisiones que pueden tomar la decisión de desarrollar, adherir o incorporar otros instrumentos existentes y ejecutar lo decidido para igualar la relación entre las partes. Este sería otro modo de alentar y procurar una remisión explícita a los Principios del Pacto Mundial.

A pesar de lo anterior, no en todos los ámbitos existe la misma fuerza proteccionista; sin duda, hay desbalance entre ellos.

Así, en relación con las prácticas enfocadas en la protección de los derechos humanos, cabe destacar que las únicas luces que se vislumbran son aportadas por el TLC celebrado con Canadá, cuyo Preámbulo contiene dos referencias generales: de un lado, al considerar que los Estados han de impulsar a las empresas a respetar "los estándares y principios de responsabilidad social empresarial internacionalmente reconocidos" $\mathrm{y}$, de otro, al afirmar el compromiso de ambos Estados en "la promoción y protección de los derechos humanos y las libertades fundamentales" contenidos en la Declaración Universal de los Derechos Humanos.

Por la dinámica de los acuerdos comerciales, negociados al margen de consideraciones sobre obligaciones de derechos humanos y en ausencia de compromisos expresos al respecto, el Pacto Mundial puede erigirse como norma referente, sin dejar de lado que, desde una perspectiva de 
derechos humanos, lo efectivo jurídicamente son las regulaciones vinculantes por encima de documentos Soft Law. En el Acuerdo con Canadá se aprecia una remisión implícita a la DUDH y la cláusula sobre RSE. Por otra parte, la protección de los derechos humanos en el marco del desarrollo del tratado con Estados Unidos dependerá de la protección a partir de las obligaciones internacionales contraídas por cada Estado contratante a la cual estén sometidas las empresas de su jurisdicción. Lo anterior no limita ni excluye la posibilidad de articular la conducta de las empresas a la luz de documentos voluntarios sobre derechos humanos y empresa o RSE como el Pacto Mundial y los Principios Rectores. Sin embargo, no es una alternativa que se derive de ese tratado.

A pesar de que las remisiones y las relaciones que puedan establecerse entre los TLC citados y el Pacto Mundial en asuntos de derechos humanos no saltan a la vista, es necesario dar al Pacto Mundial el rol principal que está llamado a desempeñar en la escena del comercio internacional. Dicho rol, fundamentado en el respeto a los derechos humanos fundamentales y marcado por el voluntarismo de los preceptos, debería guiar el actuar de las empresas en todas sus esferas de influencia.

Desde el componente que desarrolla las prácticas orientadas hacia la protección de los derechos laborales, se destaca que el texto del Tratado con Estados Unidos contiene prácticas explícitas de responsabilidad social al respecto. A pesar de que no se hace remisión expresa al Pacto Mundial, el apartado de asuntos laborales recoge los principios que derivan de este. El Capítulo XVII se dedica a los asuntos laborales. Las partes reafirman sus obligaciones como miembros de la OIT y, por tanto, su compromiso en la protección de los principios y derechos internacionalmente reconocidos.

Ahora bien, en cuanto al TLC con Canadá, aunque el texto no hace remisiones específicas a las prácticas de RSC, al igual que en el TLC suscrito con Estados Unidos, se infiere una protección de los derechos laborales en armonía con tales prácticas. Esto se evidencia en el Capítulo XVI sobre los asuntos laborales. Es pertinente señalar que ambos Estados ratifican y reconocen sus obligaciones como miembros de la OIT y, por ello, se comprometen a evitar el debilitamiento de la legislación laboral, so pretexto del comercio o la inversión.

Los tratados de libre comercio suscritos por Colombia con Canadá y Estados Unidos hacen jurídicamente vinculante la observancia de prácti- 
cas de responsabilidad social en materia de protección del ambiente; sin embargo, como ya se anotó, no son las reunidas en el Pacto Mundial, sino propias o particulares de los acuerdos alcanzados.

La redacción de los tratados permite inferir una considerable preocupación por los impactos ambientales que puedan derivarse del comercio internacional entre los Estados.

Al revisar el cuerpo de los TLC con Estados Unidos y Canadá, se aprecia la presencia de obligaciones y compromisos ambientales y un tratamiento diferencial a partir de instrumentos adicionales de protección. De la misma forma, ambos tratados incorporan la creación de órganos especializados para implementar, hacer seguimiento, evaluar y corregir los compromisos suscritos. Lo anterior, a pesar de que no existe remisión al Pacto Mundial.

Es posible que los órganos especializados, que gozan de cierta autonomía para decidir asuntos atinentes a la protección ambiental, puedan tomar la decisión de adherir a los Principios del Pacto Mundial; sería una posibilidad de acatamiento indirecto.

De no tomarse la decisión, como pasa con todos los instrumentos que ratifican compromisos de protección ambiental, lo importante no es la forma, sino el fondo, por lo que se debe garantizar el cumplimiento y la ejecución efectiva de las obligaciones impuestas.

Hubiera sido ideal recurrir de manera directa a este instrumento, por lo que se recomienda obrar en este sentido para la discusión de los tratados que se suscriban en adelante.

Ahora bien, desde el componente de lucha anticorrupción, no hay consideraciones explícitas a las prácticas que deben llevar a cabo las empresas. No obstante, en el TLC con Estados Unidos, el Capítulo XIX hace alusión expresa a la transparencia, con lo que apela al Principio $10 \mathrm{del}$ Pacto Mundial.

En el TLC con Canadá tampoco existen consideraciones explícitas a las prácticas que deben llevar a cabo las empresas, aunque se manifiesta el interés por tener mecanismos y procesos que garanticen la transparencia. Así, se presenta la misma situación que en el tratado con Estados Unidos, ya que en el Capítulo XIX se instituyen las principales orientaciones sobre el tema.

En este contexto, es imperante avanzar en la comprensión de las relaciones entre los tratados internacionales, su efecto -desde la perspectiva 
del Pacto Mundial- en las operaciones empresariales y la conceptualización que se puede inferir de una realidad sujeta a investigación empírica. Por tal razón, el siguiente paso lógico sería hacer un estudio en terreno que permita entender si estas remisiones -explícitas e implícitas- de los tratados de libre comercio al Pacto Mundial motivan acciones o iniciativas de responsabilidad social que necesitarían una cualificación posterior, objeto de otra investigación.

\section{Referencias}

Aaronson, S. y Higham, I. (2014). Putting the Blame on Governments. Why Firms and Governments have Failed to Advance the Guiding Principles on Business and Human Rights. Recuperado de http://www2.gwu.edu/ iiep/assets/docs/ papers/2014WP/AaronsonHingham201406.pdf

Boyle, A. (2010). Soft Law in International Law-Making. En M. Evans (ed.), International Law (pp. 119-133). Oxford: Oxford University Press

CGC, CGT y CUT. (2009). Declaración del Movimiento Sindical colombiano frente al Acuerdo de Cooperación Laboral del TLC entre Colombia y Canadá. Recuperado de http://www.bwint.org/pdfs/DECLARACI0N\%20MOVIMIENTO\%20 SINDICAL\%20COLOMBIANO.pdf

Cinde. (2010). En Colombia aumenta el trabajo en un $34 \%$... pero el trabajo infantil. Recuperado de http://www.cinde.org.co/PDF/En\%20Colombia\%20aumenta\%20el\%20trabajo\%20en\%20un\%2034.pdf

Colombia, Congreso de la República. (2007). Ley 1143 de 2007, Acuerdo de promoción comercial entre la República de Colombia y los Estados Unidos de América.

Colombia, Congreso de la República. (2009). Ley 1363 de 2009, Acuerdo de libre comercio entre Canadá y la República de Colombia.

Colombia, Corte Constitucional. (2008). Sentencia C-750 de 2008. M. P. Clara Inés Vargas Hernández.

Colombia, Corte Constitucional. (2010). Sentencia C-608 de 2010. M. P. Humberto Antonio Sierra Porto.

Corte Interamericana de Derechos Humanos. (1986). La expresión "Leyes" en el Artículo 30 de la Convención Americana sobre Derechos Humanos. Opinión Consultiva. Recuperado de http://www.hchr.org.co/acnudh/index.php?option=com_con tentEview=articleGid=3639:opinion-consultiva-oc-686-la-expresion-qleyesq- 
en-el-articulo-30-dela-convencion-americana-sobre-derechos-humanos\&catid $=149$ :estados-de-excepcionsItemid $=120$

Corte Interamericana de Derechos Humanos. (2004). Informe 44/04. Caso Laura Tena Colunga y otros, México. Recuperado de https://www.cidh.oas.org/ annualrep/2004sp/Mexico.2584.02.htm

Corte Interamericana de Derechos Humanos. (2009). Sentencia Caso González y otras ("Campo algodonero") vs. México, de excepción preliminar, fondo, reparaciones $y$ costas.

Cortina, A. (1997). La ética de la sociedad civil: hacer reforma. 3a ed. Madrid: Anaya. Flores Palacios, M. (2009). Reseña de "Primero la gente: una mirada desde la ética del desarrollo a los principales problemas del mundo globalizado" de Amartya Sen y Bernardo Kliksberg. Revista de Humanidades, (26), 181-185.

González, J., Salcedo, D. y Rangel, L. (2011). Impactos en los derechos humanos de la implementación del Tratado de Libre Comercio entre Colombia y Canadá. Línea base. Medellín: Escuela Nacional Sindical.

Human Rights Watch. (2013). World Report. Colombia. Recuperado de http://www. hrw.org/world-report/2013/country-chapters/colombia

IPEC. (s. f). Colombia Child Labour Data Country Brief. Recuperado de http://www. ilo.org/ipecinfo/product/download.do?type $=$ document $\mathrm{Eid}=7794$

López Medina, D. (2013). Pan y rosas: el TLC con EE UU y el futuro (incierto) del Derecho Laboral colombiano. Ámbito Jurídico. Recuperado de http://www. ambitojuridico.com/BancoConocimiento/N/noti-120417-16\%28pan_y_rosas_el_tlc_con_ee_uu_y_el_futuro_\%28incierto\%29_del_derecho_laboral_ colombiano\%29/noti-120417-16\%28pan_y_rosas_el_tlc_con_ee_uu_y_el_ futuro_\%28incierto\%29_del_derecho_laboral_colombiano\%29.asp?Miga=1

Martin-Ortega, O. (2008). Empresas multinacionales y derechos humanos en Derecho Internacional. Barcelona: Bosch.

Martin-Ortega, O. (2013). La diligencia debida de las empresas en materia de Derechos Humanos. En F. J. Zamora, J. García Cívico y L. Sales Pallarés (eds.), La responsabilidad de las multinacionales por violaciones de derechos humanos (pp. 167-192). Madrid: Universidad de Alcalá.

Méndez, M. (2005). Ética y responsabilidad social corporativa. Ética y Economía, (823), 141-150.

Moreno, A. (2007). La letra menuda del TLC. Bogotá: GEW.

Motta Cárdenas, F. (2009). El Derecho Laboral colombiano y el tratado de libre comercio TLC entre Colombia y Estados Unidos. Revista Republicana, (6), 115-128.

Oficina del Alto Comisionado de las Naciones Unidas, Oficina del Pacto Mundial de Naciones Unidas. (s. f). Integrando los derechos humanos en la práctica empre- 
sarial. Recuperado de http://proyectoredandina.files.wordpress.com/2010/03/ Mundial-compact-integrando-derehumanos.pdf

Oficina del Alto Comisionado para las Naciones Unidas. (2015). Pacto mundial de Naciones Unidas. A Guide for Business: How to Develop a Human Rights Policy. 2a ed. Nueva York: UN Global Compact.

ONU, Consejo de Derechos Humanos. (2011). Informe del representante especial del secretario general para la cuestión de los derechos humanos y las empresas transnacionales $y$ otras empresas John Ruggie. Recuperado en http://www2.ohchr.org/ SPdocs/Business/A-HRC-17-31_sp.doc

Organización de Estados Americanos. (1969). Convención americana sobre derechos humanos suscrita en la Conferencia especializada interamericana sobre derechos humanos. Recuperado de http://www.oas.org/dil/esp/tratados_B-32_Convencion_Americana_sobre_Derechos_Humanos_firmas.htm

Organización de Estados Americanos. (2013). Estado actual de firmas y ratificaciones de los tratados interamericanos. Recuperado de http://www.oas.org/es/sla/ddi/ tratados_multilaterales_interamericanos_firmas_estados.asp

Organización de Naciones Unidas. (1966). Optional Protocol to the International Covenant on Civil and Political Rights. Recuperado de https://treaties.un.org/ pages/ViewDetails.aspx?src=TREATY\&mtdsg_no=IV-5\&chapter=4\&lang=en Organización de Naciones Unidas. (2004). Observación general No. 31. Naturaleza de la obligación jurídica general impuesta a los Estados parte en el Pacto. Recuperado de http://www.refworld.org/cgi-bin/texis/vtx/rwmain/opendocpdf. pdf?reldoc $=$ y\&docid $=478 \mathrm{~b} 26 \mathrm{ea} 2$

Organización de Naciones Unidas. (2013). Recuperado de http://www.pactomundial.org/global-compact/

Ostau de Lafont, F. (1996). Tratado del derecho del trabajo. Bogotá: Ibáñez.

Ramasastry, A. (2015). Corporate Social Responsibility versus Business and Human Rights: Bridging the Gap between Responsibility and Accountability. Journal of Human Rights, 14(2), 237-259.

Ruggie, J. G. (2014). Global Governance and "New Governance Theory": Lessons from Business and Human Rights. Global Governance 20(1), 5-17.

Teitelbaum, A. (2007). Sociedades transnacionales y derechos humanos. Bogotá: ILSA. 
